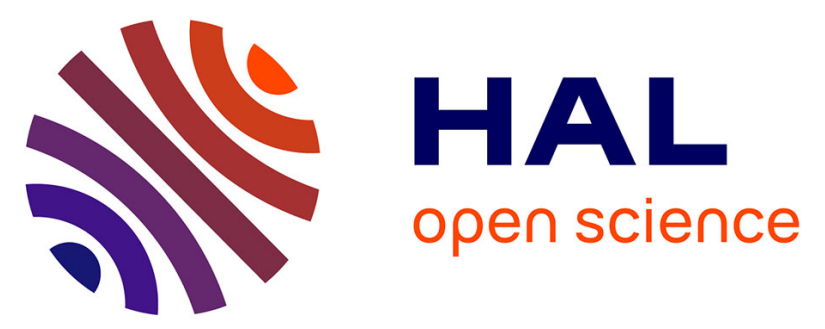

\title{
Identifying the stress-strain curve of materials by microimpact testing. Application on pure copper, pure iron, and aluminum alloy 6061-T651
}

Halim Al Baïda, Cécile Langlade, Guillaume Kermouche, R.R. Ambriz

\section{To cite this version:}

Halim Al Baïda, Cécile Langlade, Guillaume Kermouche, R.R. Ambriz. Identifying the stress-strain curve of materials by microimpact testing. Application on pure copper, pure iron, and aluminum alloy 6061-T651. Journal of Materials Research, 2015, 30 (14), pp.2222-2230. 10.1557/jmr.2015.186 . emse-01499521

\section{HAL Id: emse-01499521 \\ https://hal-emse.ccsd.cnrs.fr/emse-01499521}

Submitted on 9 Sep 2021

HAL is a multi-disciplinary open access archive for the deposit and dissemination of scientific research documents, whether they are published or not. The documents may come from teaching and research institutions in France or abroad, or from public or private research centers.
L'archive ouverte pluridisciplinaire HAL, est destinée au dépôt et à la diffusion de documents scientifiques de niveau recherche, publiés ou non, émanant des établissements d'enseignement et de recherche français ou étrangers, des laboratoires publics ou privés.

\section{(c)(1)}

Distributed under a Creative Commons Attribution| 4.0 International License 


\title{
Identifying the stress-strain curve of materials by microimpact testing. Application on pure copper, pure iron, and aluminum alloy 6061-T651
}

\author{
Halim Al Baida and Cécile Langlade ${ }^{\text {a) }}$ \\ Université Bourgogne Franche-Comté, UTBM, IRTES-LERMPS EA 7274, 90010 Belfort, France \\ Guillaume Kermouche \\ Ecole des Mines de Saint-Etienne, Centre SMS, LGF UMR 5307 CNRS, \\ 42023 Saint-Étienne, France \\ Ricardo Rafael Ambriz \\ Instituto Politécnico Nacional CIITEC-IPN, Cerrada de Cecati S/N, Col. Sta. Catarina, \\ C.P. 02250 Azcapotzalco, DF, Mexico
}

\begin{abstract}
The mechanical response of materials under repeated impact loading is of primary importance to model different types of surface mechanical treatments, such as shot peening. A reverse identification method of stress-strain curves using repeated impact has been developed by Kermouche et al. [Kermouche et al., Mater. Sci. Eng., A 569, 71-77 (2013)] and later improved by Al Baida et al. [Al Baida et al., Mech. Mater. 86, 11-20 (2015)]. This study deals with the experimental validation of this method on three materials: a home-made pure iron, a commercially pure copper, and an industrial aluminum alloy. An approximate method derived from cone indentation theory to check the reverse method reliability. Balls of different sizes have been used to cover a wide enough range of strain. The results are also compared with macroscopic compression and traction tests. The effect of the strain rate on the stress-strain curve is discussed. The conclusion section highlights the rapidity and the ease of use of the reverse identification method.
\end{abstract}

\section{INTRODUCTION}

Wide range of engineering parts require specific treatment to improve their mechanical and/or corrosion resistance to enhance the fatigue (life), as well as the deformation resistance. For such purposes, shot peening is one of the favorite candidates. The principle of this process is to impact the metallic surface to be treated using small steel balls that create plastic strain, improve hardness, induce compressive residual stress, and increase the fatigue strength. ${ }^{1}$

To better control and predict this well-known process, finite elements method (FEM) simulation of multiple impacts has been developed, ${ }^{2-4}$ but the accuracy of such model is limited by the use of pertinent stress-strain behavior laws. Johnson-Cook [Eq. (1)] or Hollomon's [Eq. (2)] laws are generally introduced into the models, but determining the correct values of the material parameters is a great challenge.

Contributing Editor: George M. Pharr

a) Address all correspondence to this author.

e-mail: cecile.langlade@utbm.fr

$$
\sigma=\left(A+B\left(\varepsilon^{\mathrm{p}}\right)^{n}\right)\left(1+C \ln \left(\frac{\dot{\varepsilon}^{\mathrm{p}}}{\varepsilon_{0}}\right)\right)\left(1-T^{* m}\right)
$$

where $\varepsilon^{\mathrm{p}}$ is the equivalent plastic strain, $A$ is the yield strength, $\dot{\varepsilon}^{\mathrm{p}} / \varepsilon_{0}$ is the normalized plastic strain rate for $\varepsilon_{0}=1.0 / \mathrm{s}, n$ is the hardening exponent, $C$ is the strain rate sensibility coefficient, $T^{*}$ is the homologous temperature, and $B$ and $m$ are constants.

$$
\sigma=k \varepsilon^{n}
$$

where $k$ is the strength coefficient, and $n$ is the strain hardening exponent.

Considering the dynamic aspect of shot peening, dynamic impact tests, such as split Hopkinson pressure bars (SHBP), may be performed to obtain the dynamic behavior law and, therefore, the material parameter, ${ }^{5}$ but these techniques can only reflect the bulk behavior of the tested materials and cannot take into account the specific surface behavior that may be predominant during shot peening tests. Other authors identify the local behavior by quasi-static instrumented indentations. ${ }^{6-8}$ If such methods enhance surface effects, static conditions cannot reveal the dynamic effect of shot peening. To combine the dynamic effect and microscale analyses, a microimpact 
testing apparatus was developed and instrumented where $2 \mathrm{~mm}$ diameter balls are punched into the sample surface at controlled energy. ${ }^{9,10}$ This experimental setup enables to perform repeated impacts at the same point and, therefore, to follow the progressive plastic deformation that may be induced by the cyclic loadings. In parallel to the experimental work, an inverse method was developed to obtain the stress-strain curve of metallic materials from the experimental results. In accordance with many other authors, ${ }^{6,11,12}$ Hollomon's law has been chosen to describe the usual behavior of the tested metals. In addition to the inverse method, an analytical approach has been used to obtain an estimation of the stress-strain curve. The use of this second method aims at testing the validity of the inverse identification and increasing the confidence in the obtained results. These two methods have been described and validated using virtual and real, but ideal material, i.e., commercially pure copper. ${ }^{13}$ In the previous work, ${ }^{13}$ the inverse method was tested in a strain range between 0.6 and 0.8 , and information about the low strain range was missing because only $2 \mathrm{~mm}$ diameter balls were used resulting in a reduced strain field. In the present paper, dynamic tests have been performed with balls of different sizes to obtain lower strain values and collect more experimental data. Besides, this study also presents applications of both the inverse method and the analytical approach to several industrial materials.

\section{THE MICROIMPACT MACHINE}

The microimpact machine is based on a micromarking machine that has been modified to project balls with controlled speed and position. This machine is equipped with a force and a displacement sensor connected to a complete acquisition chain, which allows to obtain the impact speed, i.e., the impact energy, as well as the induced force as a function of time during each single impact. By adjusting the pulse duration in the electromagnet and initial impactor position, the impact speed can vary from 100 to $600 \mathrm{~mm} / \mathrm{s}$, which corresponds to an impact energy ranging from 1 to $31 \mathrm{~mJ}$. New ball holders have been developed to allow the microimpactor to project balls from 2 to $20 \mathrm{~mm}$ diameter. The microimpactor can be used in dynamic regime as well as under static condition by manually punching the ball onto the sample surface following the standard Brinell hardness procedure. The Eq. (3) shows that the strain $\varepsilon$ is inversely proportional to $R$ (the radius of the ball) and $a$ (the radius of the residual imprint). According to this equation, $1 \mathrm{~mm}$ radius balls allow to achieve the highest deformation domain, whereas 5 and $3 \mathrm{~mm}$ radius balls induce low deformation.

$$
\varepsilon=0.2 \frac{a}{R}
$$

\section{THE FINITE ELEMENT MODEL}

The objective of the FEM simulation is to obtain the impact load and the radius of the residual imprint after 10 impacts at a given energy to develop databases that will be used in the inverse method. Repeated impacts were modeled with a finite element model developed in ABAQUS-Explicit. ${ }^{14}$ This model was already described in a previous work. ${ }^{13}$ Figure 1 shows the FEM model, the substrate is considered as semi-infinite solid with a behavior law related to $k$ and $n$ Hollomon parameters, and the ball is a $1 \mathrm{~mm}$ radius deformable elastic solid. To validate this model, the simulated load signal was compared with the experimental load signal and the calculated force value ${ }^{15}$ under pure elastic conditions. A typical error of $9 \%$ has been observed on M2 treated samples. ${ }^{13}$

The same databases presented in Al Baida et al. ${ }^{13}$ have been used in the present study.

\section{THE ANALYTICAL APPROACH}

Based on Tabor, Johnson and Hill, ${ }^{15-17}$ Kermouche et al. ${ }^{18}$ presented a direct method to estimate the local stress-strain curve of materials under sharp indentation test. This method has already been described in the case of spherical indentation in Al Baida et al. ${ }^{13}$ and validated by blind tests on virtual materials and real tests on pure copper. Based on the mean pressure, the radius of residual imprint, and the elastic properties of the tested materials, stress-strain values can be obtained.

The analytical equations of stress and strain can be written as follows:

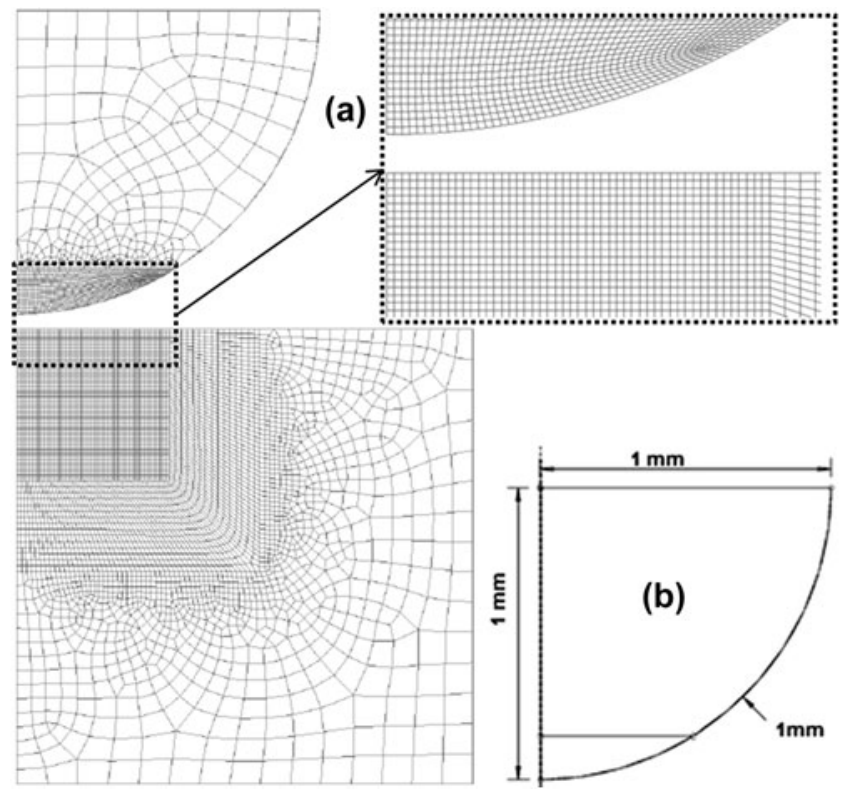

FIG. 1. FEM model for simulating the impact test: (a) complete model and (b) ball dimension. 


$$
\begin{aligned}
\sigma_{\mathrm{r}} & =\frac{\zeta \frac{a}{R} P_{\mathrm{m}}}{\gamma_{\mathrm{p}} \zeta \frac{a}{R}-(1-\zeta B) \frac{P_{\mathrm{m}}}{E}} \\
\varepsilon_{\mathrm{r}} & =(1-\zeta B) \frac{\sigma_{\mathrm{r}}}{E}+\zeta \frac{a}{R}
\end{aligned}
$$

In the previous expression [Eq. (4)], the mean pressure can be written as: $P_{\mathrm{m}}=L / \pi a^{2}$, where $L$ is the applied load, and $a$ is the contact radius. The value of $\gamma_{\mathrm{p}}$ has been fixed equal to 2.8 , as suggested by Tabor. ${ }^{17}$ The value of $B$ is equal to $\left(1-v^{2}\right) *\left(3.3^{*} \pi / 4\right)$ and $\zeta$ is given by the following equation:

$$
\zeta=\frac{4}{3 \pi \gamma_{p}\left(1-v^{2}\right)}
$$

$R$ is linked to the indenter geometry, so this value is known. The elastic properties of the materials being also known, the value of $B$ and $\zeta$ can be deduced. Considering the experimental values obtained for load and radius, $P_{\mathrm{m}}$ can be calculated and the stress-strain values for the tested materials can be determined. However, the main advantage of the analytical approach is that it can provide data on the behavior of materials in both low and high-strain range using different ball sizes.

The efficiency of the analytical approach was tested during sharp indentations in Kermouche et al. ${ }^{18}$ Figure 2 shows a comparison between the analytical approach using the spherical indentation and the static compression test of pure copper. A good correlation between analytical approach results and the static curve can be observed. If the yield stress of the tested materials cannot be identified using the analytical approach, the plastic deformation regime is well described.

\section{A. Blind tests on analytical approach}

As the efficiency of the analytical approach was validated under static conditions, the next step is to determine the accuracy of the analytical approach under dynamic impacts. For that purpose, blind tests were conducted using virtual materials assumed to be following Hollomon's law.

Virtual materials have been tested with different values of $k$ and $n$ for $8 \mathrm{~mJ}$ impact energy. The elastic properties have been chosen as $E=210 \mathrm{GPa}$ and $v=0.3$. The parameters $k$ and $n$ are as follows:

$k:(800 ; 1500 ; 2800 ; 3300) \mathrm{MPa}$, $n:(0.12 ; 0.25 ; 0.35 ; 0.47)$.

Figure 3 presents the relative error [Eq. (7)] during $N=10$ impacts between the Hollomon original stress $f_{\mathrm{o}}(\varepsilon)$ [Eq. (2)] and the predicted stress $f_{\mathrm{p}}(\varepsilon)$ obtained by the analytical approach [Eq. (4)].

$$
E_{\mathrm{r}}=100 \frac{\sqrt{\int_{\varepsilon_{1}}^{\varepsilon_{N}}\left[f_{\mathrm{o}}(\varepsilon)-f_{\mathrm{p}}(\varepsilon)\right]^{2} \mathrm{~d} \varepsilon}}{\sqrt{\int_{\varepsilon_{1}}^{\varepsilon_{N}}\left[f_{\mathrm{o}}(\varepsilon)\right]^{2} \mathrm{~d} \varepsilon}} .
$$

Figure 3 shows that the error does not exceed $6 \%$.

The error shows that the analytical approach allows to propose a good estimation of the stress-strain values using dynamic impact. These results then

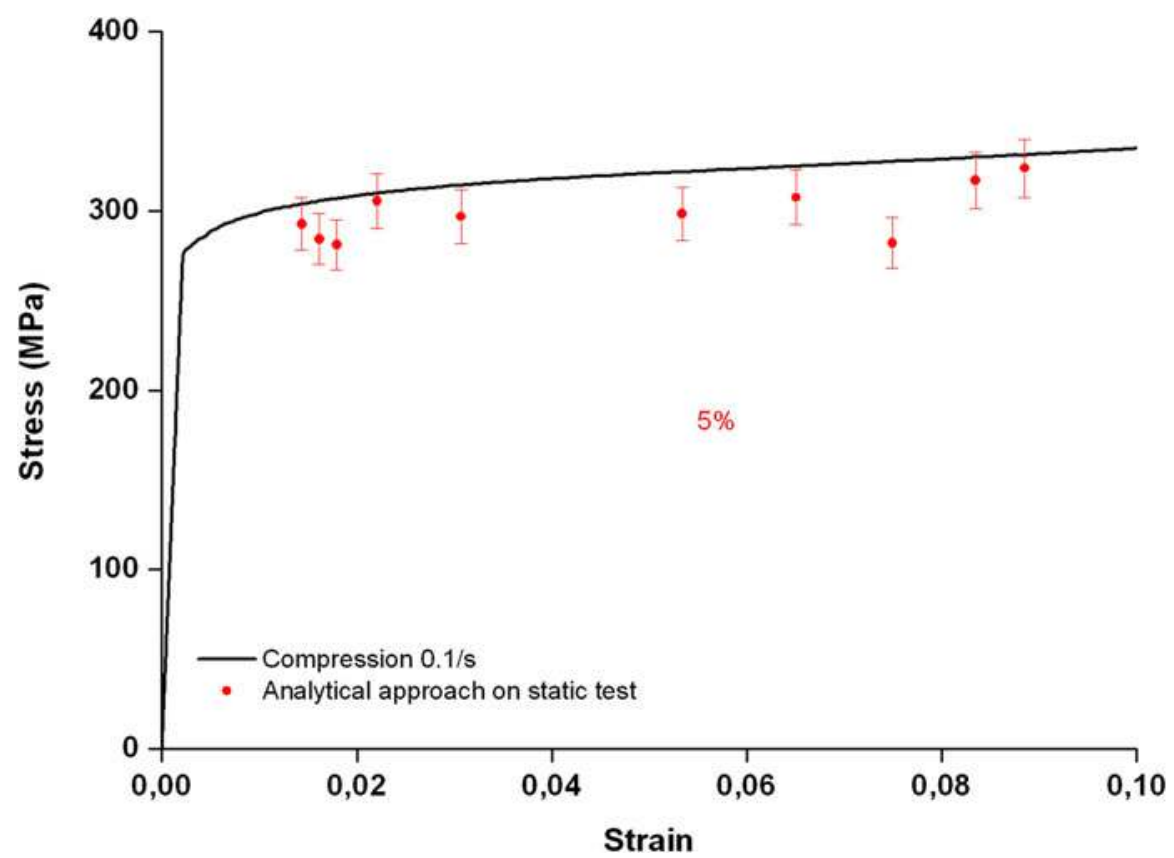

FIG. 2. Comparison between stress-strain curve of commercially pure copper under static compression and stress strain values obtained from analytical approach. 


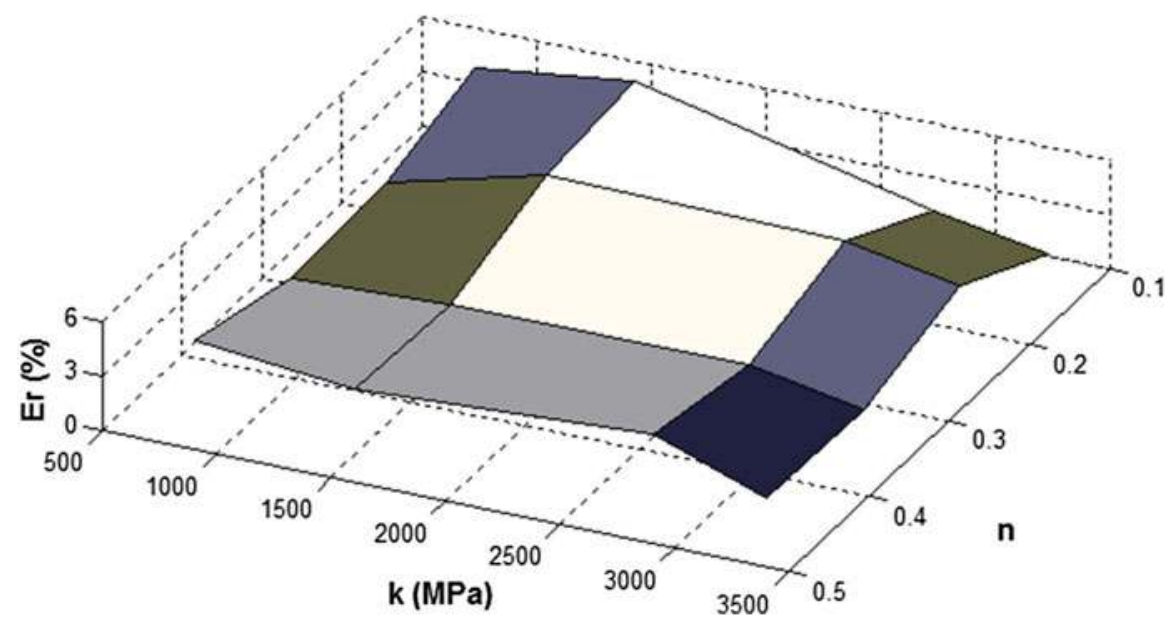

FIG. 3. Relative error $E_{\mathrm{r}}$ of Eq. (7) as function of $k$ and $n$, impact energy was $8 \mathrm{~mJ}$.

validate the use of the analytical method under dynamic impact conditions.

\section{THE INVERSE METHOD}

The inverse method has been developed by Kermouche et al. ${ }^{9}$ to identify the local stress-strain curve using dynamic impact tests. This method was first based on the comparison between experimental results of radius and depth of residual imprints, and their corresponding values obtained from FEM simulations with several $k$ and $n$ parameters of the Hollomon's law $\left(\sigma=k \varepsilon^{n}\right)$. The method and associated databases have been developed for several impact energies. The inverse method identifies the values of $k$ and $n$, which allow to reach the best approach between the experimental results and those of the FEM simulation. Figure 4 represents the general principle of the inverse method.

Referring to Kermouche et al., ${ }^{9}$ the evolution of the load and radius values as a function of the number of impacts $(N=1-10)$ can be described by the following equation:

$$
x(N)=A_{x} \ln (N)^{2}+B_{x} \ln (N)+C_{x},
$$

where $N$ is the number of impacts, $x$ is the characteristic parameter of the impact, i.e., radius $r$ and/or load $f$. As the simulations have been done for an already known impact energy, $A_{x}, B_{x}$, and $C_{x}$ are functions of ( $k$ and $n$ ) couple and describe the global evolution of $x$, they are stored in 2 databases, one for the radius $\left(A_{r}, B_{r}\right.$, and $\left.C_{r}\right)$ and one for the load $\left(A_{l}, B_{l}, C_{l}\right)$.

The experimental values of the radius of residual imprint and impact load after $N$ impacts for a given energy can be noted $r_{e}(N)$ and $f_{e}(N)$, whereas $r(N)$ and $f(N)$ are the radius and load values resulting from the FEM simulation.

Considering the experimental curves $r_{e}(N)$ and $f_{e}(N)$ and the curves of FEM simulation $r(N)$ and $f(N)$, an identification method was developed to seek the minimal

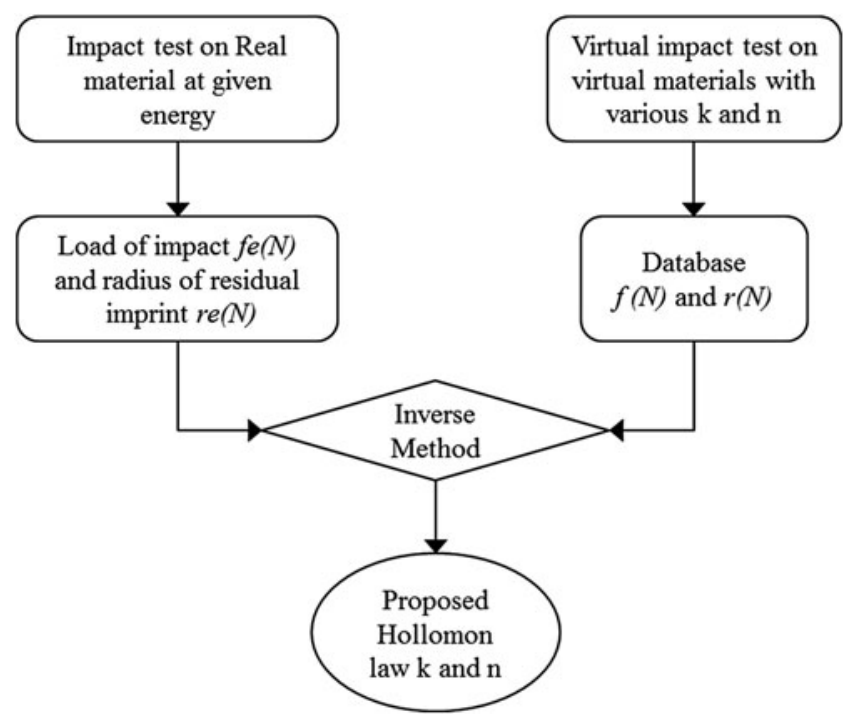

FIG. 4. Flow diagram explaining the identification of the stress-strain curve using inverse method.

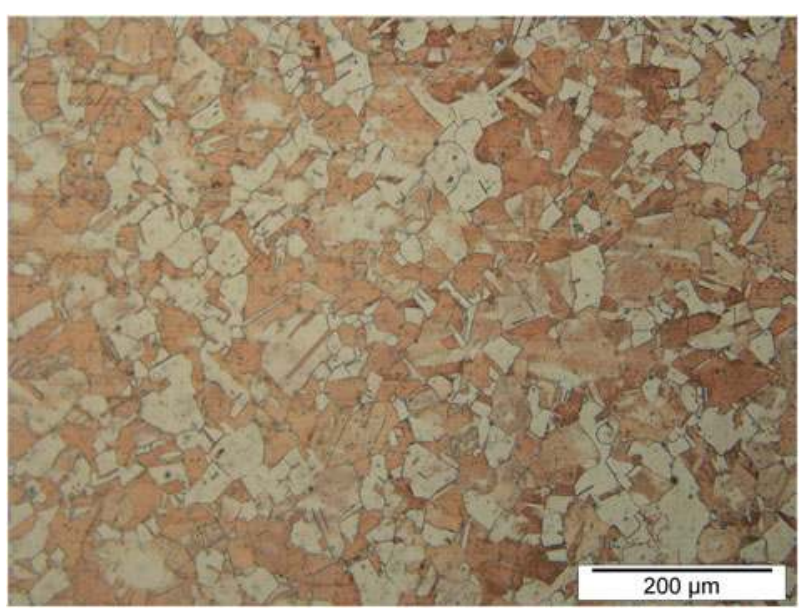

FIG. 5. Grain size of commercially pure copper. 
gap between the experimental and numerical curves and propose the best couple of $k$ and $n$ parameters of the constitutive law. This optimization method is based on the following equation:

$$
\operatorname{Minimum}\left[I_{x}(k, n)=100 \frac{\sqrt{\int_{0}^{N \max }\left(x-x_{\exp }\right)^{2} \mathrm{~d} N}}{\sqrt{\int_{0}^{N \max }(x)^{2} \mathrm{~d} N}}\right] .
$$

If the accuracy of this method has been already validated by blind tests on virtual materials and through real tests on ideal materials like pure

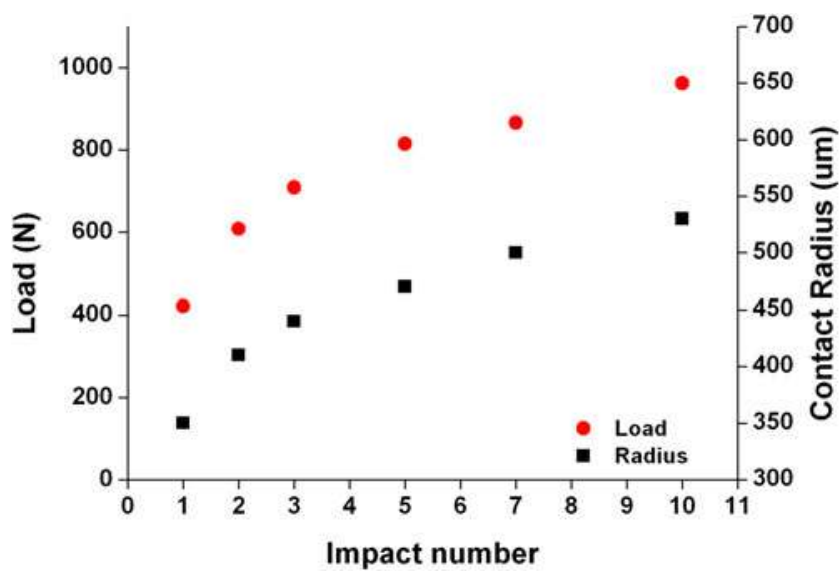

FIG. 6. Evolution of the radius (resp. load) on commercially pure copper as a function of the number of impacts using an impact energy of $11 \mathrm{~mJ}$ and a $2 \mathrm{~mm}$ diameter ball. copper, ${ }^{13}$ its use and pertinence have still to be demonstrated on industrial materials and compared with other experimental tests.

\section{EXPERIMENTAL TESTING}

Ten successive dynamic impacts at controlled energies have been performed using zirconia balls ranging from 2 to $10 \mathrm{~mm}$ diameter and $6 \mathrm{~mm}$ diameter $100 \mathrm{Cr} 6$ ball. The inverse method was applied on the results of impact load and radii of the residual imprints after ten dynamic impacts using $2 \mathrm{~mm}$ diameter ball to identify a constitutive law. The analytical approach has been applied on all impact results and compared with the inverse method results. To assess the dynamic effect, the inverse method and analytical approach results are compared with the stressstrain curve of compression test or static traction test.

Based on Mok, ${ }^{19}$ the strain rate was estimated from Eq. (10).

$$
\dot{\varepsilon}=0.2 \frac{v}{a},
$$

where $v$ is the impact velocity and $a$ the scar radius.

In this study, tested materials are pure copper, pure iron, and aluminum 6061-T651.

\section{A. Application on pure copper}

Commercially pure copper samples have been chosen for the first tests. As shown in Fig. 5, the microstructure consists of fine equiaxed grains involving an isotropic material behavior. Figure 6 shows the evolution of radius

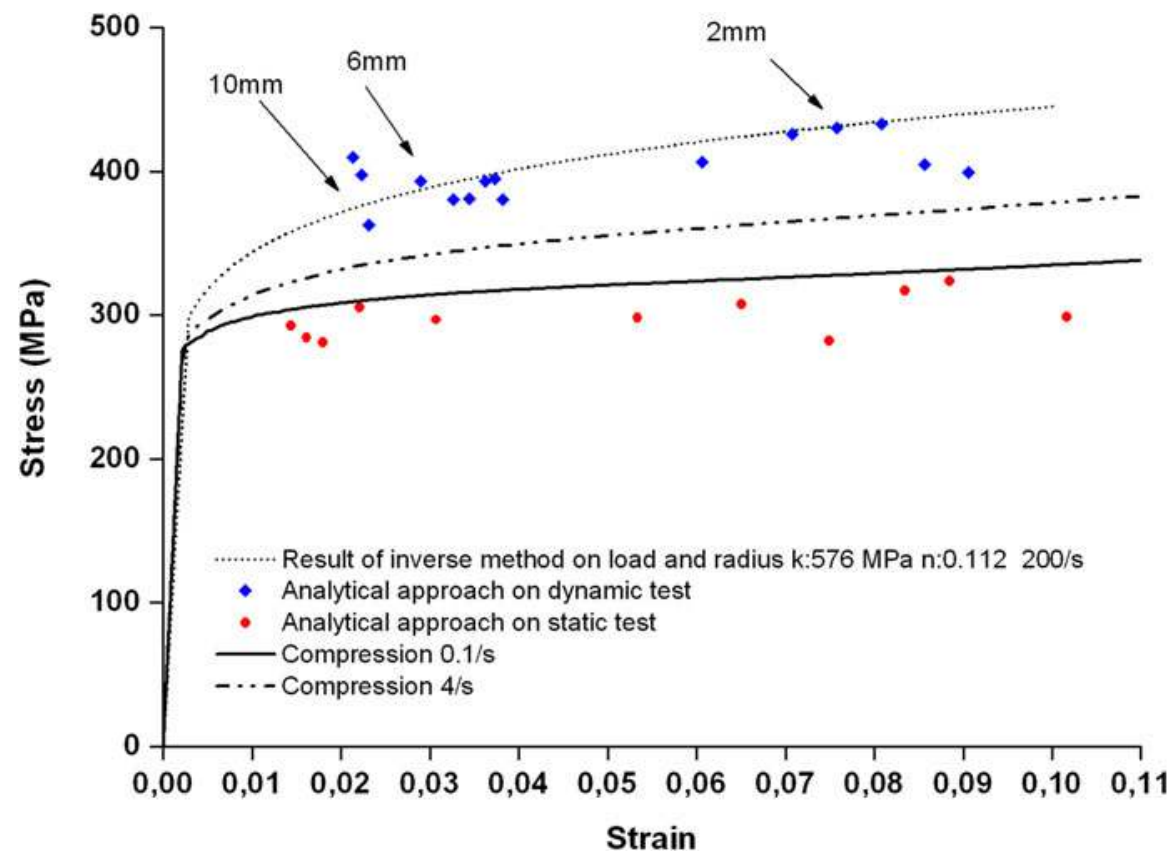

FIG. 7. Comparison between stress-strain curves obtained by compression test at two strain rates on commercially pure copper, the result of the inverse method, and the result of the analytical approach in dynamic and static case using 2, 6, and $10 \mathrm{~mm}$ diameter ball sizes. 
and load during 10 successive impacts for $11 \mathrm{~mJ}$ using $2 \mathrm{~mm}$ diameter balls.

Figure 7 summarizes the different results obtained on copper samples. 2 compression curves are plotted for 2 different strain rates, i.e., 0.1 and $4 \mathrm{~s}^{-1}$. They clearly illustrate the influence of the strain rate showing that increasing the strain rate leads to a shift of the curve to higher stress levels. The analytical method has then been applied on static indentation results, and the corresponding points (red points) are plotted in Fig. 7, showing a quite good agreement with the static compression test $\left(0.1 \mathrm{~s}^{-1}\right)$. This confirms the pertinence of the analytical method for identifying static stress-strain curves from static spherical indentation. It also suggests that the strain rate imposed during spherical indentation may be slightly lower than $0.1 \mathrm{~s}^{-1}$. The Analytical method has also been applied on dynamic impacts obtained using 3 different ball types leading to a second set of points (blue points) on Fig. 7. Then the inverse method was launched on the $2 \mathrm{~mm}$ ball impacts to propose a dynamic stress-strain curve. The analytical points and the stress-strain law proposed through the inverse method are quite similar. These results confirm the influence of the strain rate on the stress-strain curve.

Considering the classical Johnson Cook equation [Eq. (1)], a strain rate sensibility coefficient of $C=0.038$ may be deduced from the compression curve at $4 \mathrm{~s}^{-1}$ and the dynamic impact stress-strain curve using Eq. (11). It can be noted that in the case of OFHC copper, the value of $C=0.025$ can be found in the literature. ${ }^{20-22}$

$$
C=\frac{\left(\sigma_{1}-\sigma_{2}\right)}{\sigma_{2} \ln \dot{\varepsilon}_{1}-\sigma_{1} \ln \dot{\varepsilon}_{2}} .
$$

\section{B. Application on pure iron}

To test the efficiency of the inverse method, pure Iron BCC substrate (99:9997\% iron) cylinders of $11 \mathrm{~mm}$

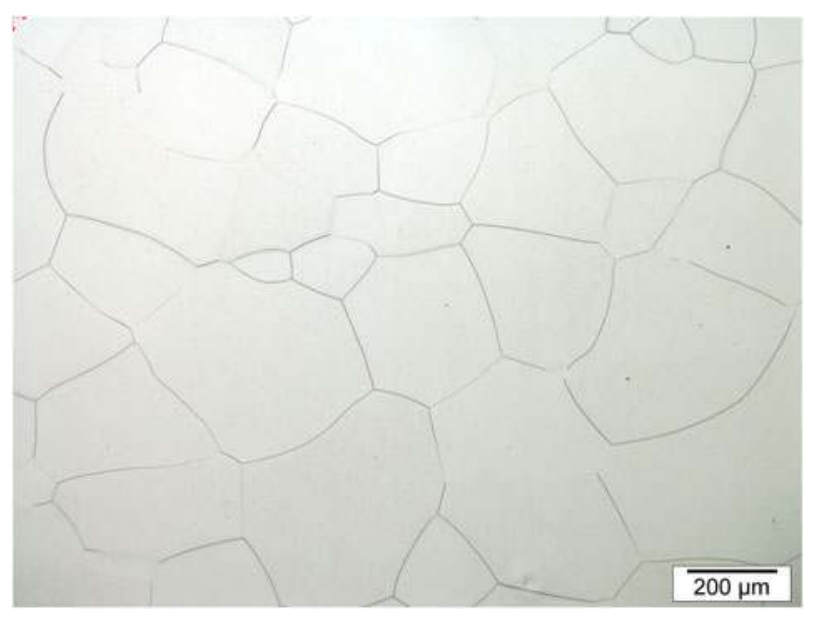

FIG. 8. Microstructure of pure iron. diameter and $5 \mathrm{~mm}$ thick obtained by cold crucible melting $^{23}$ have been chosen. The mean grain size at $280 \mu \mathrm{m}$ can be observed in the microstructure picture (Fig. 8). Figure 9 shows the evolution of impact radius and induced load on pure iron samples as a function of the number of impacts at $17 \mathrm{~mJ}$ using a $2 \mathrm{~mm}$ diameter ball. These values have then been used as input data for the inverse method (Fig. 4). Figure 10 summarizes the results of compression tests at two different strain rates, the result of the inverse method and the result of the analytical approach using ball size 2, 6, and $10 \mathrm{~mm}$ of diameter. It can first be noted that the analytical approach is in good agreement with the results of the inverse method. Moreover, according to Fig. 10, a large gap of $60 \%$ can be observed between the two compression curves obtained at different strain rates, demonstrating the high sensitivity of iron to the strain rate. ${ }^{24}$ The analytical method has also been applied on dynamic and static impacts using the 3 different diameter ball sizes. The inverse method using the $2 \mathrm{~mm}$ ball impacts enables to propose a dynamic stress-strain curve. The stressstrain law proposed through the inverse method fits the analytical points with a reasonable agreement and confirms the influence of the strain rate on the stress-strain curve. Considering the compression curve at $4 \mathrm{~s}^{-1}$, the dynamic impact stress-strain curve and Eq. (11), a strain rate sensibility coefficient of $C=0.11$ may be determined. Reference values of $C=0.06$ may be found in the literature for Armco pure iron. ${ }^{20}$ Higher values are noted for carbon or tool steels.

\section{Application on aluminum (6061-T651)}

Similarly to the tests performed on copper and iron, the inverse method has been applied on Aluminum 6061-T651 at $10 \mathrm{~mJ}$, the same inverse method result has been presented in a recent study. ${ }^{25}$ Both analytical and inverse methods have been used to identify the stress-strain curve of this industrial material. The results

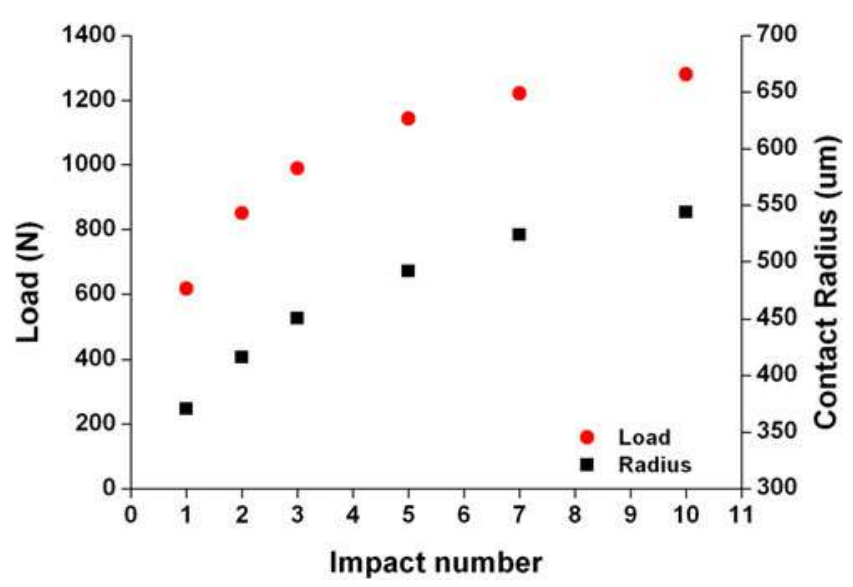

FIG. 9. Growth of radius (load) on pure iron with the number of impact for impact energy of $17 \mathrm{~mJ}$ using a $2 \mathrm{~mm}$ diameter ball. 
have been compared with quasi-static traction tests performed at CIITEC-IPN in Mexico. ${ }^{26}$ Figure 11 confirms the good correlation between the analytical approach and the result of the inverse method and/or the tensile test. These results show that the proposed methods are also suitable for industrial materials likely to have heterogeneities. Despite the nonideal microstructure, the two methods can be used with a limited variability leading to the determination of a dynamic stress-strain curve. Regarding iron and copper, a shift toward higher stresses clearly appears with a higher yield stress about $30 \%$.

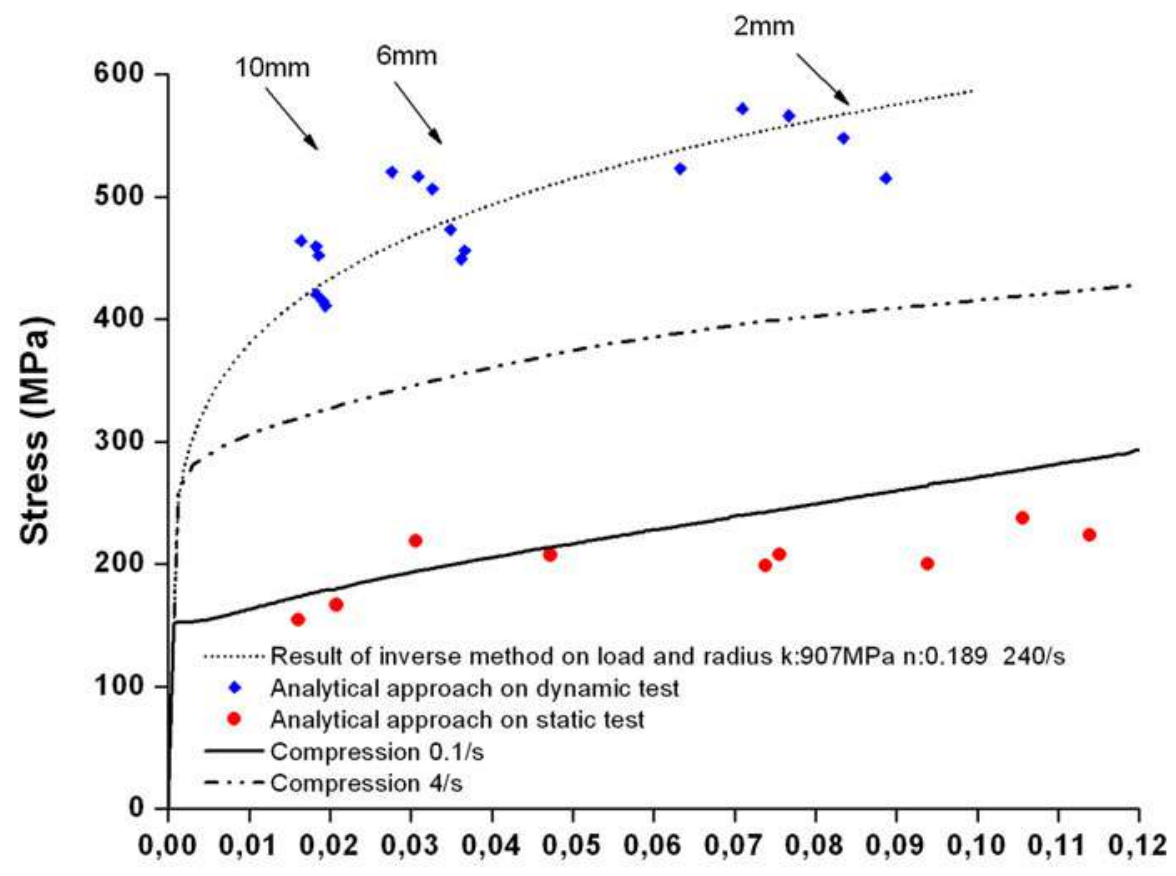

Strain

FIG. 10. Comparison between the stress-strain curves obtained by compression test at two strain rates on pure iron, results of the inverse method, and results of the analytical approach in dynamic and static case using 2, 6, and $10 \mathrm{~mm}$ diameter ball sizes.

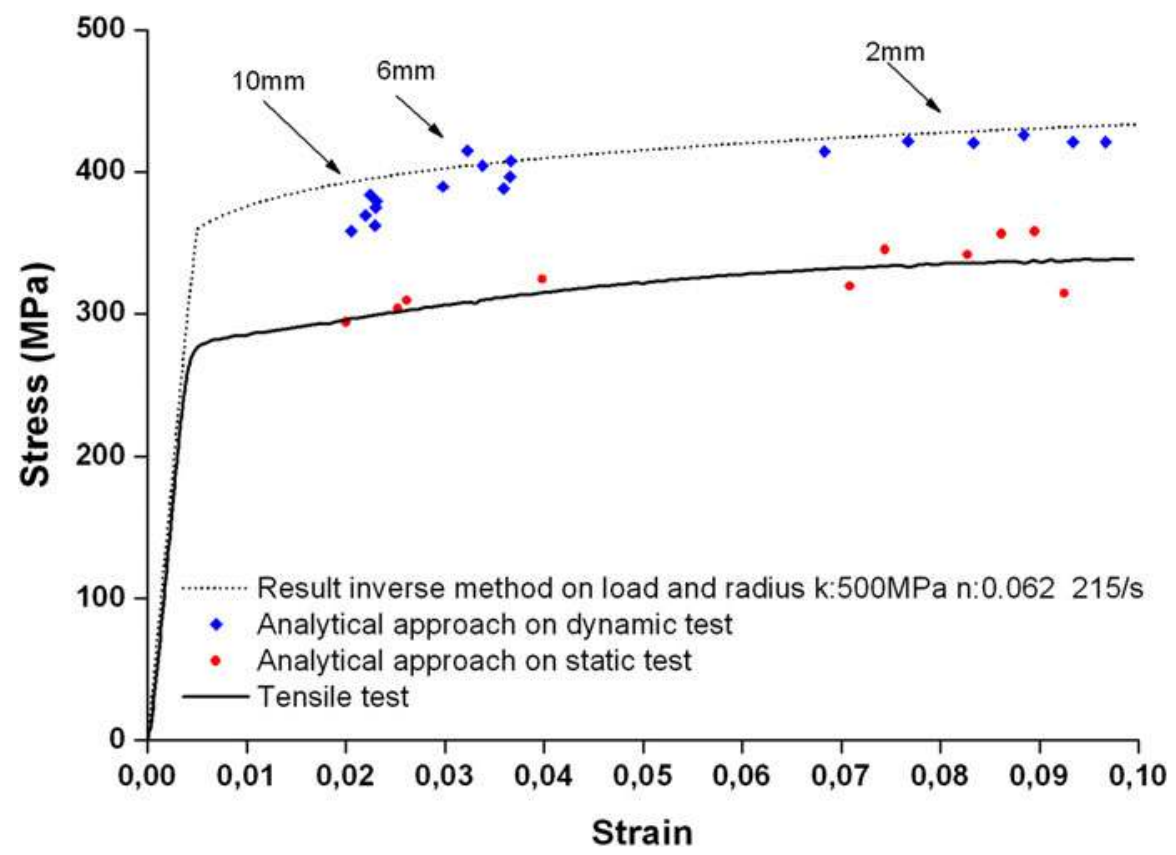

FIG. 11. Comparison between the tensile test on aluminum 6061-T651, inverse method, and analytical approach (using 2, 6, and $10 \mathrm{~mm}$ diameter ball sizes). 


\section{CONCLUSION}

This study presents an application of an inverse method to identify the stress-strain curve of materials subjected to high speed impacts like those occurring during the shot peening process. The inverse method was presented in Al Baida et al., ${ }^{13}$ and it was validated by blind tests on virtual materials and by experimental results on commercially pure copper. This present work presents new applications on ideal materials like pure iron or commercially pure copper but also on an industrial aluminum 6061-T651. It also presents a comparison between the inverse method results and a direct analytical approach. This direct approach being only established for static sharp tip indentation, this work enables to state its validity for both static and dynamic spherical indentation. The results obtained for the three ideal and industrial materials show a good correlation between the inverse method and the analytical approach results. Numerical blind tests enable to estimate its accuracy and show that an approximate stress-strain curve of the materials within a $15 \%$ margin of error may be expected (estimate on virtual materials).

When a static traction or compression curve is available, the dynamic impact method also permits to give an estimation of the strain rate sensibility coefficient of Johnson Cook equation.

As this technique does not require large volumes of material or specific samples, its use may be a promising method to obtain static and dynamic stress-strain curves of all kinds of materials. Furthermore, considering the small volume of the impacted zone, it can be sensitive to surface treatment effects (shot peening, nitriding, coatings, welding, etc.), i.e., domains that are difficult to characterize using conventional techniques.

\section{ACKNOWLEDGMENT}

The authors gratefully acknowledge financial support from UTBM and the international relations that allocated funds for Mr. RR Ambriz as a visiting professor. They also wish to thank Mr. D. Schlegel and Mr. Th. Couturier for their help in the design and implementation of various indenter-holders and Mr. D. Tumbajoy for his help in the sample preparation and compression tests on pure iron and pure copper.

\section{REFERENCES}

1. V.O. Abramov, O.V. Abramov, F. Sommer, O.M. Gradov, and O.M. Smirnov: Surface hardening of metals by ultrasonically accelerated small metal balls. Ultrasonics 36, 1013-1019 (1998).

2. H.Y. Miao, D. Demers, S. Larose, C. Perron, and M. Lévesque: Experimental study of shot peening and stress peen forming. J. Mater. Process. Technol. 210, 2089-2102 (2010).

3. K. Murugaratnam, S. Utili, and N. Petrinic: A combined DEM-FEM numerical method for shot peening parameter optimization. Adv. Eng. Softw. 79, 13-26 (2015).
4. G.I. Mylonas and G. Labeas: Numerical modelling of shot peening process and corresponding products: Residual stress, surface roughness and cold work prediction. Surf. Coat. Technol. 205, 4480-4494 (2011).

5. S.P.F.C. Jaspers and J.H. Dautzenberg: Material behaviour in conditions similar to metal cutting: Flow stress in the primary shear zone. J. Mater. Process. Technol. 122, 322-330 (2002).

6. M. Beghini, L. Bertini, and V. Fontanari: Evaluation of the stress-strain curve of metallic materials by spherical indentation. Int. J. Solids Struct. 43, 2441-2459 (2006).

7. J-M. Collin, G. Mauvoisin, O. Bartier, R. El Abdi, and P. Pilvin: Experimental evaluation of the stress-strain curve by continuous indentation using different indenter shapes. Mater. Sci. Eng., A 501, 140-145 (2009).

8. J-M. Collin, G. Mauvoisin, P. Pilvin, and R. El Abdi: Use of spherical indentation data changes to materials characterization based on a new multiple cyclic loading protocol. Mater. Sci. Eng., A 488, 608-622 (2008).

9. G. Kermouche, F. Grange, and C. Langlade: Local identification of the stress-strain curves of metals at a high strain rate using repeated micro-impact testing. Mater. Sci. Eng., A 569, 71-77 (2013).

10. S. Lamri, C. Langlade, and G. Kermouche: Damage phenomena of thin hard coatings submitted to repeated impacts: Influence of the substrate and film properties. Mater. Sci. Eng., A 560, 296-305 (2013).

11. M. Dao, K. Chollacoop, K.J. Van Vliet, T.A. Venkatesh, and S. Suresh: Computational modeling of the forward and reverse problems in instrumented sharp indentation. Acta Mater. 49, 3899-3918 (2001).

12. Y. Huang, X. Liu, Y. Zhou, Z. Ma, and C. Lu: Mathematical analysis on the uniqueness of reverse algorithm for measuring elastic-plastic properties by sharp indentation. J. Mater. Sci. Technol. 27, 577-584 (2011).

13. H. Al Baida, G. Kermouche, and C. Langlade: Development of an improved method for identifying material stress-strain curve using repeated micro-impact testing. Mech. Mater. 86, 11-20 (2015).

14. D. Systems: Abaqus Explicit (2011).

15. K.L. Johnson: Contact Mechanics (Cambridge University Press, Cambridge, UK, 1985).

16. R. Hill, B. Storakers, and A.B. Zdunek: A theoretical study of the Brinell hardness test. Proc. R. Soc. London, Ser. A 423, 301-330 (1989).

17. D. Tabor: The Hardness of Metals (Oxford University Press, Oxford, UK, 2000).

18. G. Kermouche, J-L. Loubet, and J-M. Bergheau: An approximate solution to the problem of cone or wedge indentation of elastoplastic solids. C. R. Méc. 333, 389-395 (2005).

19. C-H. Mok: The dependence of yield stress on strain rate as determined from ball-indentation tests. Exp. Mech. 6, 87-92 (1966).

20. G.R. Johnson and W.H. Cook: Fracture characteristics of three metals subjected to various strains, strain rates, temperatures and pressures. Eng. Fract. Mech. 21, 31-48 (1985).

21. M.A. Meyers: Dynamic Behavior of Materials (John Wiley \& Sons, Hoboken, NJ, 1994).

22. C. Peng, Y. Zhong, Y. Lu, S. Narayanan, T. Zhu, and J. Lou: Strain rate dependent mechanical properties in single crystal nickel nanowires. Appl. Phys. Lett. 102, 083102 (2013).

23. V. Lacaille, G. Kermouche, D-Y.T. Spinel, E. Feulvarch, C. Morel, and J-M. Bergheau: Modeling nitriding enhancement resulting from the NanoPeening treatment of a pure iron. IOP Conf. Ser. Mater. Sci. Eng. 63, 012124 (2014).

24. D. Ostwaldt, J.R. Klepaczko, and P. Klimanek: Compression tests of polycrystalline $\alpha$-iron up to high strains over a large range of strain rates. J. Phys. IV 07, 385-390 (1997). 
25. H. Al Baida, C. Langlade, G. Kermouche, and R. Ambriz: Identification du comportement mécanique des matériaux à l'aide d'essais de micro-impact répétés. Matér. Tech. 102, 604 (2014).
26. R.R. Ambriz, C. Froustey, and G. Mesmacque: Determination of the tensile behavior at middle strain rate of AA6061-T6 aluminum alloy welds. Int. J. Impact Eng. 60, 107-119 (2013). 